\title{
Global Survey of the Roles, Satisfaction, and Barriers of Home Health Care Nurses on the Provision of Palliative Care
}

\author{
Jeannine M. Brant, PhD, APRN, AOCN, FAAN, ${ }^{1}$ Regina M. Fink, RN, PhD, AOCN, FAAN, ${ }^{2}$ \\ Cara Thompson, RN, MSN, ${ }^{3}$ Ya Huei Li, PhD, ${ }^{4}$ Maryam Rassouli, PhD, RN, ${ }^{5}$ Tomoko Majima, PhD, ${ }^{6}$ \\ Tomoko Osuka, MSN, ${ }^{6}$ Nahla Gafer, MD, ${ }^{7}$ Ayfer Ayden, $\mathrm{PhD},{ }^{8}$ Khaled Khader, MSN, ${ }^{9}$ Eulalia Lascar, MD, ${ }^{10}$ \\ Lili Tang, MD, ${ }^{11}$ Sophia Nestoros, MD, ${ }^{12}$ Maihan Abdullah, MD, ${ }^{13}$ Natasha Michael, MD, ${ }^{14}$ Julie Cerruti, PhD, ${ }^{15}$ \\ Eric Ngaho, RN, ${ }^{16}$ Yolanda Kadig, MSc, ${ }^{17}$ Mohamed Hablas, MD, ${ }^{18}$ Rana Istambouli, MSc, ${ }^{19,20}$ \\ Mary A. Muckaden, MD, ${ }^{21}$ Mushtaq Najm Ali, RN, ${ }^{22}$ Bella Aligolshvili, MSN, ${ }^{23}$ Rana Obeidat, PhD, ${ }^{24}$ \\ Gulnara Kunirova, DSPsy, ${ }^{25}$ Ma'an Al-Omari, MSN, ${ }^{26}$ Mohammad Qadire, PhD, ${ }^{27}$ Suha Omran, PhD, ${ }^{28}$ \\ Marie C. Mouhawej, RN, ${ }^{29}$ Mohcine Zouak, MD, ${ }^{30}$ Ibtisam Ghrayeb, MSN, ${ }^{31}$ Nemeh Manasrah, MSN, ${ }^{32}$ \\ Alexey Youssef, MD, ${ }^{33}$ Paz F. Ortega, PhD, ${ }^{34}$ Gonca Tuncel Oguz, MD, ${ }^{35}$ \\ Loyda Amor N. Cajucom, BSN, RN, MAN, ${ }^{36}$ Kassie Leaphart, BSN, ${ }^{37}$ \\ Alexa Day, BSN, ${ }^{38}$ and Michael Silbermann, DMD, PhD ${ }^{39}$
}

\footnotetext{
${ }^{1}$ Collaborative Science and Innovation, Billings Clinic, Montana State University College of Nursing, Billings, Montana.

${ }^{2}$ College of Nursing and School of Medicine, University of Colorado, Aurora, Colorado.

${ }^{3}$ Palliative Care, University of Colorado Health, Aurora, Colorado.

${ }^{4}$ Collaborative Science and Innovation, Billings Clinic, Billings, Montana.

${ }^{5}$ Shahid Beheshti, University of Medical Sciences Cancer Research Center, Teheran, Iran.

${ }^{6}$ Graduate School of Nursing, Chiba University, Chiba, Japan.

${ }^{7}$ Radiation and Isotope Center, Khartoum, Sudan.

${ }^{8}$ Koç University School of Nursing, Istanbul, Turkey.

${ }^{9}$ Taif University Faculty of Nursing, Taif, Saudi Arabia.

${ }^{10}$ Hospital de Niños "Dr. Ricardo Gutierrez," Buenos Aires, Argentina.

${ }^{11}$ Department of Psychology, Peking University Cancer Hospital, Beijing, China.

${ }^{12}$ Cypriot Anticancer Society, Nicosia, Cyprus.

${ }^{13}$ Health Promotion Department, Ministry of Public Health, Kabul, Afghanistan.

${ }^{14}$ Sydney School of Medicine, University of Notre Dame, Sydney, Australia.

${ }^{15}$ Coordenadora Pesquisas Onco Pediaátricas, Porto Alegre, Brazil.

${ }^{16}$ Baptist Hospital Mutengene, Tiko, Cameroon.

${ }^{17}$ The Cyprus Association of Cancer Patients and Friends, Limassol, Cyprus.

${ }^{18}$ Al-Gharbiya Anticancer Society, Tanta, Egypt.

${ }^{19}$ Department of Palliative Care, Ain Wazein Medical Village University Hospital, Ain Wazein, Lebanon.

${ }^{20}$ Palliative Medicine, Paris, France.

${ }^{21}$ Tata Memorial Center, Mumbai, India.

${ }_{22}^{22}$ Children's Welfare Teaching Hospital, Medical City, Baghdad, Iraq.

${ }^{23}$ Home Support Services, Clalit Health Organization, Jerusalem, Israel.

${ }^{24}$ Faculty of Nursing, Zarqa University, Zarqa, Jordan.

${ }^{25}$ Kazakhstan Palliative Care Association, Almaty, Kazakhstan.

${ }^{26}$ Department of Oncology, King Abdullah University Hospital, Irbid, Jordan.

${ }^{27}$ Faculty of Nursing, Al-Bayt University, Mafraq, Jordan.

${ }^{28}$ Faculty of Nursing, Jordan University of Science and Technology, Irbid, Jordan.

${ }^{29}$ Hôtel Dieu de France, Ashrafieh, Lebanon.

${ }^{30}$ Institute of Cancer Research, Rabat, Morocco.

${ }^{31}$ Makassed Charitable Hospital, East Jerusalem.

${ }^{32}$ Faculty of Nursing, Hebron University, West Bank, Palestine.

${ }^{33}$ Faculty of Medicine, Tishrin University, Latakia, Syria.

${ }^{34}$ Catalan Institute of Oncology, Barcelona, Spain.

${ }^{35}$ Dr. Abdurrahman Yurtaslan Ankara Oncology Education \& Research Hospital, Ankara, Turkey.

${ }^{36}$ Open University of the Philippines, Los Banos, Laguna, Philippines.

${ }^{37}$ St. Vincent Healthcare, Montana State University College of Nursing, Billings, Montana.

${ }^{38}$ Billings Clinic, Montana State University College of Nursing, Billings, Montana.

${ }^{39}$ Middle East Cancer Consortium, Haifa, Israel.

Accepted January 24, 2019.
} 


\section{Abstract}

Background: The World Health Assembly urges members to build palliative care (PC) capacity as an ethical imperative. Nurses provide PC services in a variety of settings, including the home and may be the only health care professional able to access some disparate populations. Identifying current nursing services, resources, and satisfaction and barriers to nursing practice are essential to build global PC capacity.

Objective: To globally examine home health care nurses' practice, satisfaction, and barriers, regarding existing palliative home care provision.

Design: Needs assessment survey.

Setting/Subjects: Five hundred thirty-two home health care nurses in 29 countries.

Measurements: A needs assessment, developed through literature review and cognitive interviewing.

Results: Nurses from developing countries performed more duties compared with those from high-income countries, suggesting a lack of resources in developing countries. Significant barriers to providing home care exist: personnel shortages, lack of funding and policies, poor access to end-of-life or hospice services, and decreased community awareness of services provided. Respondents identified lack of time, funding, and coverages as primary educational barriers. In-person local meetings and online courses were suggested as strategies to promote learning.

Conclusions: It is imperative that home health care nurses have adequate resources to build PC capacity globally, which is so desperately needed. Nurses must be up to date on current evidence and practice within an evidence-based PC framework. Health care policy to increase necessary resources and the development of a multifaceted intervention to facilitate education about PC is indicated to build global capacity.

Keywords: cancer; community; home health; nursing; palliative care

$\mathbf{T}$ HE ROLE AND IMPORTANCE of nurses caring for persons with cancer and other chronic diseases is gaining recognition. ${ }^{1}$ Globally, nurses provide care in various settings, including hospitals, ambulatory clinics, long-term care, and homes. $^{2,3}$ Home health care requires distinct acknowledgment, as in some remote global areas, nurses may be the only health care professional able to access geographically disparate populations. Home health care nurses exhibit unique skills to address multiple health care needs with a special emphasis on palliative care (PC). ${ }^{4}$

Delivering home health care nursing across the globe has challenged nurses to assume a range of roles and responsibilities. ${ }^{5}$ Employing a culturally sensitive, patient-centered approach is the heart of nursing; clarifying contributions in improving quality of life (QOL) is essential. ${ }^{6}$ Further education and deeper recognition of the nurse's critical function as leader of the home health care team aid in empowering nurses wherever they live and work. ${ }^{7}$

\section{Background}

Each year, 40 million people are in need of PC; $14 \%$ of people actually receive it. ${ }^{8}$ In 2014 , the World Health Assembly incorporated PC into its international agenda urging member states to build PC capacity as an ethical imperative "with emphasis on primary health care, community, and home-based care.", 82015 global survey assessing capacity for prevention and control of noncommunicable diseases (NCDs) included PC questions for the first time. ${ }^{9}$ The survey indicated disparity between low- and high-income countries in lack of PC capacity, health care policy, essential palliative medication availability, and service provision. Only $36 \%$ of 177 participating countries had community PC available (i.e., "offered to at least $50 \%$ of NCD patients in need"); only $4 \%$ of low-income countries. ${ }^{10}$ Effective policy to affect systems change in PC delivery across all income groups is lacking.
The role of home health care nurses has existed formally since the 1850s. As health care delivery for NCDs shifts away from institutions back to the home, community nurses are well situated to meet growing demands of an aging population. ${ }^{11}$ However, little is known about the global primary PC practice of community nurses. A small number of studies, conducted in high-income countries, where PC capacity is more developed, have explored the role of community nurses generally ${ }^{12-15}$ or PC specifically. ${ }^{16-18}$

The paucity of research on the community nurse role in the context of PC provision hinders global progress in the relief of suffering and improving QOL for patients/families. "It is estimated that each death potentially affects the life of, on average, five people in terms of caregiving and grieving. By 2030, an estimated 74 million deaths will occur/year, increasing the number of people annually affected by death and dying to 370 million." 19 Policy initiatives to promote PC integration into community nursing and determine $\mathrm{PC}$ education needs deserve urgent attention.

\section{Purpose}

This needs assessment globally examined home health care nurses' duties, satisfaction, barriers, preferred learning methods, and country differences related to (1) PC development and capacity according to criteria identified by Lynch et al., ${ }^{20}$ and (2) income level according to the World Health Organization (WHO) World Bank. ${ }^{21}$ Results will inform development of future educational and training activities and identify overall and country-specific views and home health care provision recommendations.

\section{Methods}

We employed a convenience sample of home health care nurses. The Middle Eastern Cancer Consortium invited 
health care professionals from 42 countries to lead and coordinate respective countries' survey efforts. As recognition of time and effort, coordinators who collected $\geq 15$ completed surveys were included as authors. Each country coordinator disseminated surveys to targeted home health care nurses by Survey Monkey e-mail link or paper. Participation was voluntary; survey completion inferred consent. The Billings Clinic Institutional Review Board determined the study exempt as per U.S. regulations.

\section{Instrument development}

An extensive literature review examined research regarding home health care nursing duties, barriers, and satisfaction $^{11,14,15,17-19,22-25}$ and previously developed PC and home care needs assessment instruments. ${ }^{10,13,25-27} \mathrm{Six}$ investigators, consisting of PC and home health care nurses and students, reviewed results and developed a question bank. Cognitive interviews were conducted with a convenience sample of six U.S.-based home health care nurses to determine item relevance and clarity, offering editing suggestions. Country coordinators provided feedback to clarify medical terminology differences. For example, "physiotherapy" was added to physical therapy; "field nurse" better identified the target population. Coordinators translated surveys from English into Arabic, Spanish, Portuguese, Persian, Turkish, French, Greek, Russian, Chinese, and Japanese, and back translated to verify validity.

The final 74-item instrument takes 10-15 minutes to complete, consists of seven sections, and includes quantitative and open-ended questions addressing nurse demographics, patient population information, home health care duties, satisfaction with and barriers to provision of home health care delivery and PC, community resources available, barriers to educational opportunities, and desired learning methods (Appendix A1). Three sections include scales rated on a 0 to 3 Likert response: (1) Duties rated "never" to "always", (22 items), (2) Barriers rated "not at all" to "severe" (11 items), and (3) Satisfaction rated "very dissatisfied" to "very satisfied" (14 items).

A letter invited nurses to share perspectives on duties, conditions, work environment, and challenges faced in carrying out daily nursing functions. Surveys were distributed to 749 nurses globally from November 2017 through April 2018.

\section{Data analysis}

A descriptive analysis was conducted on nurse characteristics (age, sex, type of employment, country of current employment, highest degree, years of experience), patient care information (urban-rural classification, socioeconomic classes, patient age ranges, number of homecare visits per week), and interdisciplinary team factors (types of support staff, level of education of supporting staff, disciplines of collaboration). Participants not employed as a home health care nurse were excluded from the analysis.

Items on three survey scales (i.e., duties, barriers, satisfaction) were analyzed and reported with mean and standard deviations. Item-response theory was employed to identify subscales of the three areas (duties, satisfaction, and barriers) using Eigen-values. An exploratory factor analysis (EFA) tested associations between subscales and items; correlations $>0.35$ were maintained in that domain. Finally, a standard- ized value was developed with finalized items, which were identified in EFA and input from clinical professionals. Five subscales were identified for duties (PC, education, therapies, safety and quality, and medical care); four for satisfaction (patient/family care, access to medications/supplies, provider communication, religious support), and seven for barriers (lack of PC services, infrastructure, patient/family communication, team communication, culture/religion, language, and time).

Palliative care delivery (PCD) level, ${ }^{20}$ stratified countries into six levels: group 1 (no known hospice-PC activity), group 2 (capacity-building activity), group 3A (isolated PC provision), group 3B (generalized PC provision), group 4A (hospice-PC services with preliminary integration into mainstream service provision), and group 4B (hospice-PC services with advanced integration into mainstream service provision). Due to small respondent numbers in group 1 countries, groups 1 and 2 were combined. Additionally, countries were stratified by four WHO income levels (low, lowermiddle, upper-middle, and high) (Table 1). ${ }^{21}$ Survey subscales (i.e., duties, satisfaction, barriers) were compared using both PCD and WHO levels.

Data were entered into SPSS (Statistical Package for the Social Sciences 24.0) version $22^{28}$ Analyses were performed using SAS version 9.4. ${ }^{29}$ Chi-squared tests were performed on binomial/categorical variables for group comparisons. Analysis of variance was employed to test PCD and WHO group differences. Statistical significance was set at $\dot{\alpha}=0.05$.

\section{Results}

\section{Demographics}

Of 749 respondents, 532 were included in the final analysis representing 29 countries from 6 continents $(81 \%$ response rate). The average respondent (Table 2) was female $(80.91 \%), 37.67 \pm 11.37$ years of age, had $13.56 \pm 10.42$ years nursing experience, a bachelor's degree (44\%), employed full time $(58 \%)$, and personally visited $14.07 \pm 17.49$ patients per week. These nurses cared for men and women of all ages and incomes, in predominantly urban areas. Results are organized according to PCD level and WHO income bank in Tables 3 and 4 , respectively.

\section{Duties}

Top 5 duties performed were health maintenance $(M=2.47 \pm 0.82)$, patient $(M=2.38 \pm 0.76)$ and family $(M=2.31 \pm 0.79)$ education, emotional support $(M=2.37 \pm 0.76)$, and patient safety/quality improvement $(M=2.34+0.78)$. Regarding subscales, safety/quality was the most performed group of duties; patient/family education and shared decision making $(M=2.18+0.65)$ were second (Appendix Table A1).

When examining duties performed relative to PCD criteria, nurses in level 1 and 2 countries performed significantly more therapies and medication administration/medical care $(p<0.0001)$. They also performed more patient/family education $(p=0.6179)$ and safety/quality duties $(p=0.4011)$, although differences were not significant. Level $3 \mathrm{~A}$ performed the least amount of PC duties; this difference was significant compared with level 4A countries $(p=0.0033)$.

The WHO World Income Bank criteria aligned with some categories of PCD criteria. Low-income countries performed 
Table 1. Countries Surveyed by Palliative Care Delivery Level and World Bank Income

\begin{tabular}{|c|c|c|c|c|}
\hline Countries by WHO regions $(\mathrm{N}=29)$ & $\begin{array}{c}\text { No. of usable } \\
\text { surveys } \\
(\mathrm{N}=532)\end{array}$ & $\begin{array}{l}\text { Percentage } \\
\text { respondents }\end{array}$ & $\begin{array}{c}P C \text { delivery } \\
\text { level }\end{array}$ & $\begin{array}{c}\text { World Bank } \\
\text { income group } \\
\text { (FY2016) }\end{array}$ \\
\hline \multicolumn{5}{|l|}{ African region (2) } \\
\hline Cameroon & 15 & 2.82 & $3 \mathrm{~A}$ & Low-middle \\
\hline Rwanda & 3 & 0.56 & $3 \mathrm{~A}$ & Low \\
\hline \multicolumn{5}{|l|}{ Region of the Americas (3) } \\
\hline Argentina & 20 & 3.76 & $3 B$ & High \\
\hline Brazil & 9 & 1.69 & $3 \mathrm{~A}$ & Upper-middle \\
\hline U.S. & 19 & 3.57 & 4B & High \\
\hline \multicolumn{5}{|l|}{ Eastern Mediterranean region (12) } \\
\hline Afghanistan & 13 & 2.44 & 1 & Low \\
\hline Egypt & 16 & 3.01 & $3 \mathrm{~A}$ & Low-middle \\
\hline Iran & 60 & 11.28 & $3 \mathrm{~A}$ & Upper-middle \\
\hline Iraq & 7 & 1.32 & $3 \mathrm{~A}$ & Upper-middle \\
\hline Jordan & 47 & 8.83 & $3 \mathrm{~B}$ & Upper-middle \\
\hline Lebanon & 17 & 3.20 & $3 \mathrm{~A}$ & Low-middle \\
\hline Morocco & 13 & 2.44 & $3 \mathrm{~A}$ & Low-middle \\
\hline Palestine & 20 & 3.76 & 2 & Low-middle \\
\hline Saudi Arabia & 5 & 0.94 & $3 \mathrm{~A}$ & High \\
\hline Sudan & 11 & 2.07 & $3 \mathrm{~A}$ & Low-middle \\
\hline Syria & 1 & 0.19 & 1 & Low-middle \\
\hline UAE & 1 & 0.19 & $3 \mathrm{~A}$ & Low-middle \\
\hline \multicolumn{5}{|l|}{ European region (6) } \\
\hline Cyprus & 33 & 6.20 & $3 \mathrm{~B}$ & High \\
\hline France & 15 & 2.82 & 4B & High \\
\hline Israel & 21 & 3.95 & $4 \mathrm{~A}$ & High \\
\hline Kazakhstan & 11 & 2.07 & $3 \mathrm{~A}$ & Upper-middle \\
\hline Spain & 16 & 3.01 & $4 \mathrm{~A}$ & High \\
\hline Turkey & 46 & 8.65 & $3 \mathrm{~B}$ & Upper-middle \\
\hline \multicolumn{5}{|l|}{ Southeast Asia region (2) } \\
\hline India & 17 & 3.20 & $3 \mathrm{~B}$ & Low-middle \\
\hline Indonesia & 1 & 0.19 & $3 \mathrm{~A}$ & Low-middle \\
\hline \multicolumn{5}{|l|}{ Western Pacific region (4) } \\
\hline Australia & 15 & 2.82 & $4 B$ & High \\
\hline China & 18 & 3.38 & $4 \mathrm{~A}$ & Upper-middle \\
\hline Japan & 46 & 8.65 & $4 \mathrm{~B}$ & High \\
\hline Philippines & 16 & 3.01 & $3 \mathrm{~A}$ & Low-middle \\
\hline
\end{tabular}

PC, palliative care; WHO, World Health Organization.

significantly more PC, therapies (e.g., physical therapy [PT], occupational therapy [OT]), and medication administration/ medical care compared with other countries $(p<0.0001)$ and significantly fewer safety/quality duties $(p=0.0139)$. Nurses from high-income countries performed the least amount of therapies.

\section{Satisfiers}

Nurses were most satisfied with nurse/provider communication $(M=2.14+0.72)$ and patient/provider communication $(M=2.08+0.73)$ and most dissatisfied with patient goal discussion $(M=1.84+0.86)$, symptom management $(M=1.85+0.87)$, and patients having adequate information about care alternatives $(M=1.86+0.84)$. When subscales were examined, provider communication was again the greatest satisfier $(M=2.11+0.69)$.

Satisfaction varied by PCD level. Nurses in levels 1 and 2 were significantly less satisfied in three of four categories: patient/family care $(p<0.0001)$, provider communication $(p=0.0008)$, and religious support $(p<0.0001)$. Level 3A nurses were least satisfied with access to medications and supplies $(p<0.0001)$. Level 4A nurses were most satisfied with patient/family care, Level 3B nurses most satisfied with access to medications/supplies and provider communication, and level 3A nurses most satisfied with religious support.

The WHO and PCD criteria aligned closely in satisfaction. The one difference was that low-income countries scored lowest in all categories, including access to medications/supplies $(p<0.0001)$; nurses were most dissatisfied with patient/ family care $(M=1.05+0.61)$. When examining higher satisfaction, WHO and PCD criteria varied. High-income countries scored highest in patient/family care $(M=2.08+0.58)$, but low-middle income countries scored highest in access to medications/supplies $(M=2.09+0.69)$, provider communication $(M=2.44+0.58)$, and religious support $(M=2.37+0.81)$.

\section{Barriers}

The top 5 barriers identified included lack of personnel $(M=1.52 \pm 1.05)$, funding $(M=1.48 \pm 1.03)$, policy and guidance $(M=1.35 \pm 0.99)$, access to end-of-life or hospice 


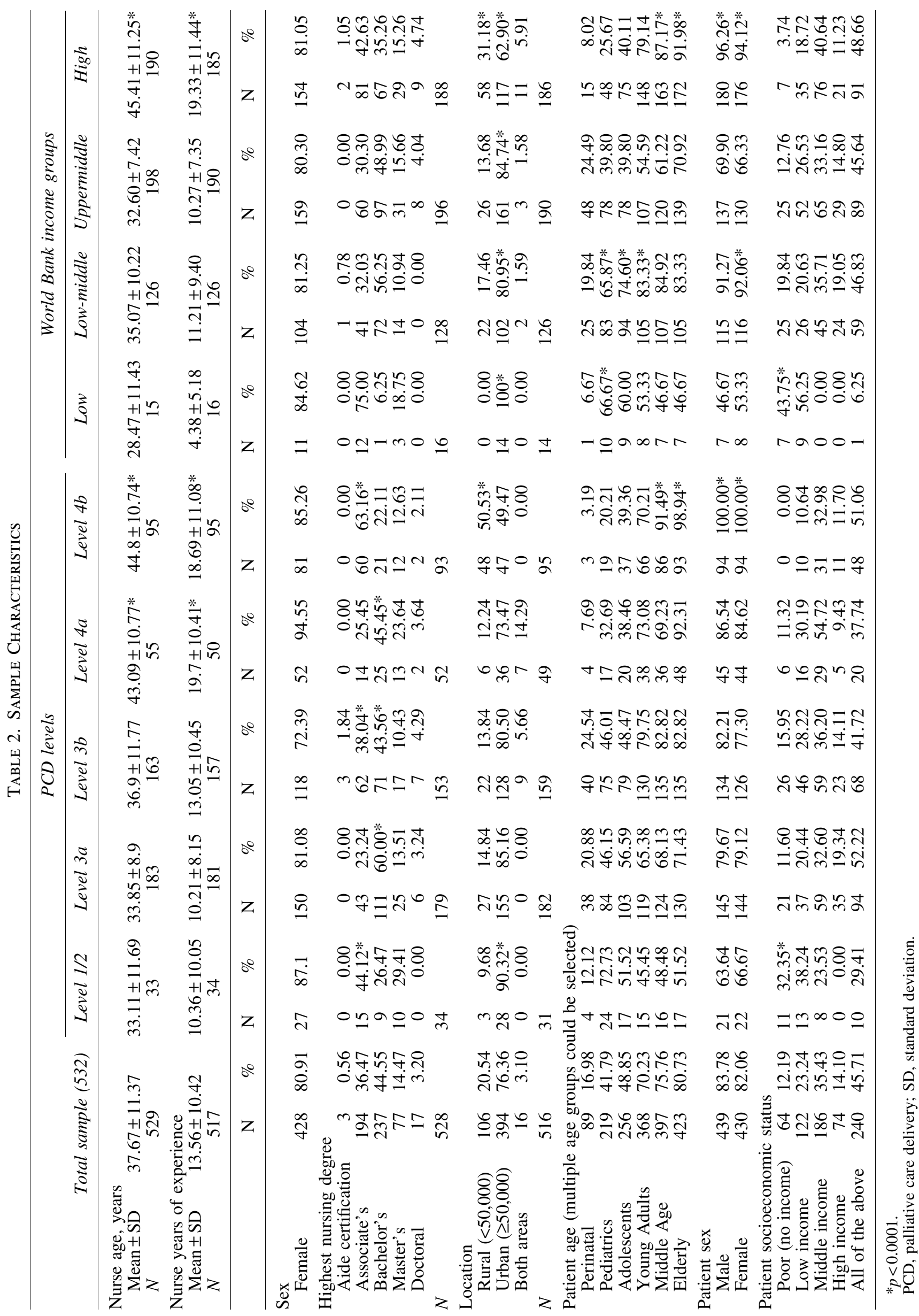




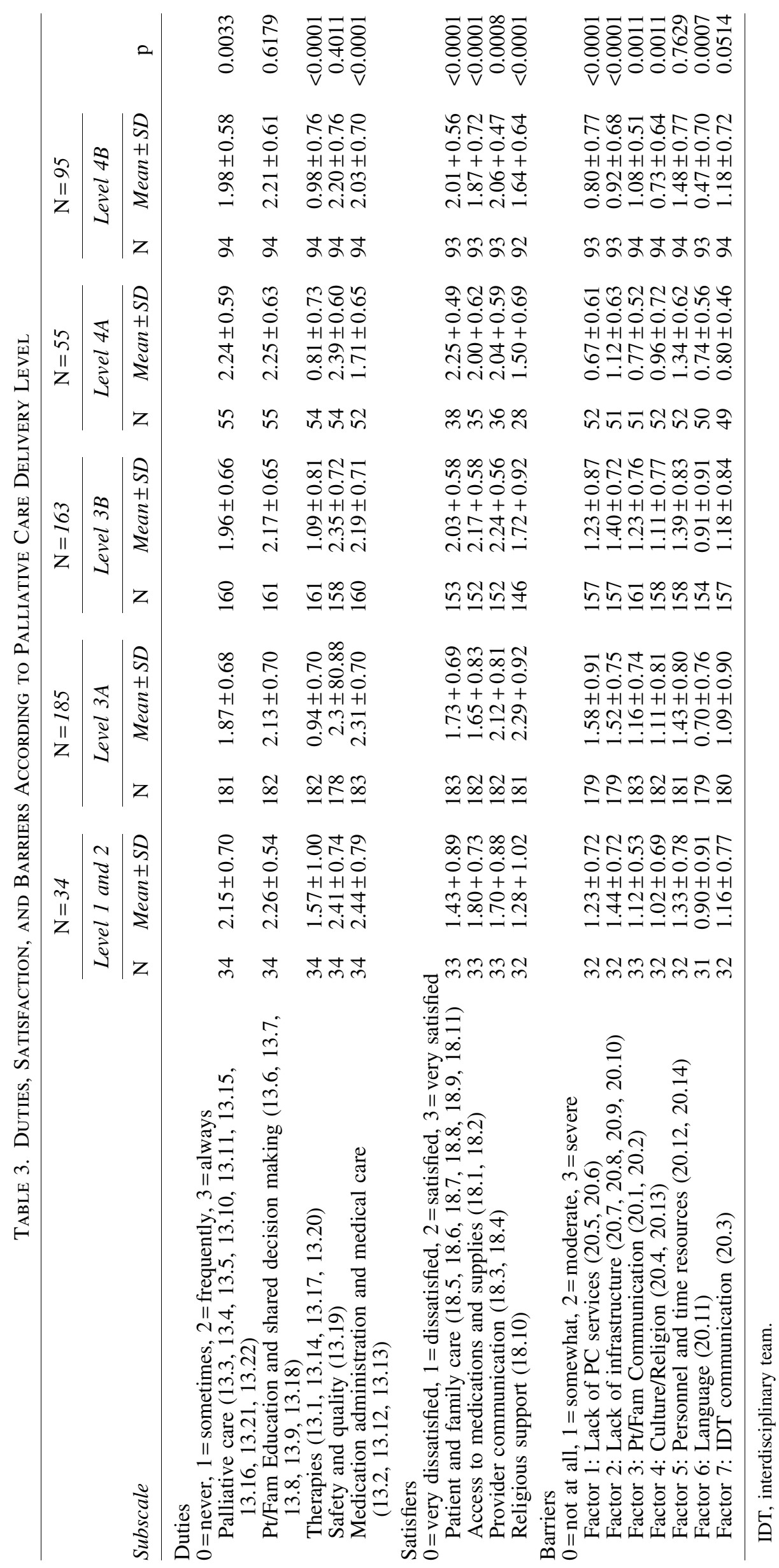


Table 4. Duties, Satisfaction, and Barriers According to World Income Bank

\begin{tabular}{|c|c|c|c|c|c|c|c|c|c|}
\hline \multirow[b]{3}{*}{ Subscale (item no.) } & \multirow{2}{*}{\multicolumn{2}{|c|}{$\frac{\mathrm{N}=16}{\text { Low-income }}$}} & \multicolumn{2}{|c|}{$\mathrm{N}=113$} & \multicolumn{2}{|c|}{$\mathrm{N}=195$} & \multicolumn{2}{|r|}{$\mathrm{N}=208$} & \multirow[b]{3}{*}{$\mathrm{p}$} \\
\hline & & & \multicolumn{2}{|c|}{ Low-middle income } & \multicolumn{2}{|c|}{ Upper middle income } & \multicolumn{2}{|c|}{ High income } & \\
\hline & $\mathrm{N}$ & $M e a n \pm S D$ & $\mathrm{~N}$ & $M e a n \pm S D$ & $\mathrm{~N}$ & $M e a n \pm S D$ & $\mathrm{~N}$ & $M e a n \pm S D$ & \\
\hline \multicolumn{10}{|l|}{ Duties } \\
\hline $\begin{array}{l}\text { Patient and family care } \\
\quad(18.5,18.6,18.7,18.8 \\
18.9,18.11)\end{array}$ & 16 & $1.05 \pm 0.61$ & 126 & $2.00 \pm 0.66$ & 191 & $1.68 \pm 0.66$ & 167 & $2.08 \pm 0.58$ & $<0.0001$ \\
\hline $\begin{array}{l}\text { Access to medications and } \\
\text { supplies }(18.1,18.2)\end{array}$ & 15 & $1.60 \pm 0.71$ & 126 & $2.09 \pm 0.69$ & 188 & $1.70 \pm 0.78$ & 166 & $1.97 \pm 0.71$ & $<0.0001$ \\
\hline $\begin{array}{l}\text { Provider communication } \\
\quad(18.3,18.4)\end{array}$ & 16 & $1.09 \pm 0.49$ & 126 & $2.44 \pm 0.58$ & 188 & $2.07 \pm 0.74$ & 166 & $2.07 \pm 0.57$ & $<0.0001$ \\
\hline Religious support (18.10) & 15 & $1.20 \pm 1.08$ & 125 & $2.37 \pm 0.81$ & 188 & $1.88 \pm 0.99$ & 151 & $1.66 \pm 0.75$ & $<0.0001$ \\
\hline \multicolumn{10}{|l|}{ Satisfaction } \\
\hline $\begin{array}{l}\text { Patient and family care } \\
\quad(18.5,18.6,18.7,18.8, \\
18.9,18.11)\end{array}$ & 16 & $1.05+0.61$ & 126 & $2.00+0.66$ & 191 & $1.68+0.66$ & 167 & $2.08+0.58$ & $<0.0001$ \\
\hline $\begin{array}{l}\text { Access to medications and } \\
\text { supplies }(18.1,18.2)\end{array}$ & 15 & $1.60+0.71$ & 126 & $2.09+0.69$ & 188 & $1.70+0.78$ & 166 & $1.97+0.71$ & $<0.0001$ \\
\hline $\begin{array}{l}\text { Provider communication } \\
\quad(18.3,18.4)\end{array}$ & 16 & $1.09+0.49$ & 126 & $2.44+0.58$ & 188 & $2.07+0.74$ & 166 & $2.07+0.57$ & $<0.0001$ \\
\hline Religious support (18.10) & 15 & $1.20+1.08$ & 125 & $2.37+0.81$ & 188 & $1.88+0.99$ & 151 & $1.66+0.75$ & $<0.0001$ \\
\hline \multicolumn{10}{|l|}{ Barriers } \\
\hline Lack of PC services $(21.5,21.6)$ & 14 & $1.11 \pm 0.49$ & 124 & $1.63 \pm 1.04$ & 194 & $1.31 \pm 0.80$ & 181 & $0.84 \pm 0.75$ & $<0.0001$ \\
\hline $\begin{array}{l}\text { Lack of infrastructure } \\
\quad(21.7,21.8,21.9,21.10)\end{array}$ & 14 & $1.29 \pm 0.71$ & 124 & $1.62 \pm 0.72$ & 193 & $1.39 \pm 0.72$ & 181 & $1.07 \pm 0.72$ & $<0.0001$ \\
\hline $\begin{array}{l}\text { Patient/Family Communication } \\
(21.1,21.2)\end{array}$ & 16 & $1.09 \pm 0.61$ & 125 & $1.30 \pm 0.69$ & 196 & $1.08 \pm 0.78$ & 185 & $1.07 \pm 0.56$ & 0.0132 \\
\hline Culture/Religion $(21.4,21.13)$ & 15 & $1.17 \pm 0.77$ & 125 & $1.3 \pm 0.78$ & 195 & $1.01 \pm 0.77$ & 183 & $0.83 \pm 0.69$ & $<0.0001$ \\
\hline $\begin{array}{l}\text { Personnel and time resources } \\
(21.12,21.14)\end{array}$ & 15 & $1.50 \pm 0.94$ & 124 & $1.46 \pm 0.80$ & 195 & $1.38 \pm 0.82$ & 183 & $1.40 \pm 0.72$ & 0.7811 \\
\hline Language (21.11) & 13 & $1.15 \pm 0.69$ & 124 & $0.77 \pm 0.81$ & 192 & $0.78 \pm 0.83$ & 178 & $0.64 \pm 0.76$ & 0.0781 \\
\hline IDT communication (21.3) & 15 & $1.20 \pm 0.94$ & 125 & $1.28 \pm 0.90$ & 192 & $1.01 \pm 0.80$ & 180 & $1.10 \pm 0.73$ & 0.0295 \\
\hline
\end{tabular}

services $(M=1.34 \pm 1.04)$, and community awareness of services provided $(M=1.29 \pm 0.84)$. When subscales were examined, personnel and time were the greatest barriers $(1.41+0.78)$ followed by lack of infrastructure $(1.33 \pm 0.75)$.

The WHO and PCD criteria aligned closely in terms of lack of PC services and infrastructure. When examining barriers by PCD criteria, nurses in level 3a expressed significantly more barriers with lack of PC services and infrastructure $(p<0.0001)$. All groups experienced a lack of personnel and time; differences were not significant by PCD.

\section{Barriers to accessing educational opportunities}

Respondents identified primary barriers to accessing education: lack of time $(n=327)$ and funding $(n=323)$, concerns about staff relief coverage $(n=303)$, and lack of availability of appropriate educational opportunities. Respondents preferred local education or in-person meetings $(76 \%)$ followed by technology-based media such as webinars and teleconferences $(51 \%)$ and online and self-learning educational courses $(40 \%)$.

\section{Discussion}

In recent decades, health and social care policies in developed and developing countries have consistently focused on two themes: shifting more care from hospitals to the community, and improving integration of PC services into the community in becoming an essential part of mainstream medical care. ${ }^{13}$ Both the Lancet Oncology Commission and American Society of Clinical Oncology (ASCO) recommend early PC integration into oncology care incorporating primary health care providers, including nurses, across inpatient, outpatient, and community settings. ${ }^{30}$ While the interdisciplinary team is a key component of the organizational model in hospitals to access PC services, community and home care outreach is critical. At the primary health care level, nurses and other clinicians need training to develop PC competence.

To date, we know little about whether we have the infrastructure and workforce necessary to make integrated community-based PC a reality. This study, the first global cross-sectional survey of nurses working in the community, has identified several gaps. It became evident that community nurses in developing countries were less satisfied with all criteria examined: care for the patient/family, patient communication, and provision of emotional/spiritual support. By contrast, community nurses in developed countries reported more satisfaction with patient care yet were less involved in direct care and prescribed drug handling. ${ }^{13}$

Many frustrations emerged related to excessive caseloads, inadequate staffing levels, lack of policy and guidance, and insufficient funding and accessibility to end-of-life measures. 
Nevertheless, increasing entrants into community nursing is clearly needed. Health care policy needs to address issues raised in the survey that reflect misuse of community nursing services, to practice at full scope, and work more efficiently and effectively. The National Consensus Project for Quality Palliative Care Guidelines calls all frontline health professionals to improve PC for all people living with serious illness, regardless of diagnosis, prognosis, care setting, and age. Clinicians with PC skills and knowledge must be available in all care settings, including the home. Five key updates in the revised guidelines include: comprehensive PC assessment; family caregiver assessment, support, and education; care coordination during care transitions, culturally inclusive PC; and communication emphasis as a means for delivering quality PC. Home health care nurses are well positioned to deliver high-quality PC; education and training is needed. ${ }^{31}$ The Coursera PC specialization, available online to nurses globally, is one educational strategy that can be used to improve PC knowledge. ${ }^{32}$

Community nursing policies across developed countries have sought to provide a solution to these pressures, mainly by restructuring nurse roles in two distinct ways: (1) developing specialist roles, and (2) developing primary care roles. ${ }^{33}$ The first approach includes expansion of nurse practice roles in Australia to encompass more clinical tasks from general practitioners, and introduction of advanced practitioner roles in England, Canada, USA, and Australia. The second fits with development of primary care roles of public health nurses, such as those in Ireland, Canada, and Scotland. ${ }^{33}$ An important issue that refers more to community nurses in developing countries involves the lack of evidence-based nursing education necessary to perform complex tasks. $^{34}$

Globally, 20 million people need PC services; $80 \%$ live in low- and middle-resource countries, where health systems are challenged to provide care for rapidly growing populations with NCDs. Because nurses are the largest workforce in global health care, they are in a strategic position to influence the quality of PC delivery across the illness trajectory. ${ }^{35}$ The very essence of nursing is focused on caring for the whole person and supporting the family through difficult situations. Today, nurses with varying levels of education and expertise provide PC to greater or lesser degrees. In most parts of the world, community nurses are not only the main health care professionals, but also the primary link between the patient/ family and other professionals both in the community and hospital. Moreover, community nurses are accountable for completing comprehensive-based interventions at home and evaluating the impact of care delivered. Providing symptom management, patient education, and emotional support for patient/family are key responsibilities. Most nurses in our survey from developing countries described their working conditions as poor and lacking appropriate time for each patient, due to understaffing, lack of resources, policy, guidance, and access to end-of-life services.

Despite the overall holistic approach in nursing care, $\mathrm{PC}$ is conceptualized as a specialty practice in several developed countries and requires additional specific knowledge and skill beyond that possessed by a general nurse. In most developing countries, nurses pursue informal, on the job, continuing education. Unfortunately, in the latter countries, PC remains a low priority and does not receive the needed financial support for PC nurse education. Additionally, nurses in both developed and developing countries are not comfortable with conversing with patients and families about death, dying, and end-of-life issues, which often leads to nurses' moral distress. ${ }^{35}$

The lack of updated training and education contributes significantly to barriers community nurses face daily, as they are asked to perform tasks requiring updated clinical skills, including communication issues, advocacy, and community mobilization. Priority should be given to funding programs for specialist post-basic or in-service training together with exchange programs that offer experiences in other practice areas such as NCDs. ${ }^{36}$ Because community nurses have more direct contact with patients/families, nurses practicing homebased PC improve patients' symptoms and sense of wellbeing, which has potential to prevent hospitalizations.

The present study explored the integration of community nurses in PC provision to patients at home. Community nurses worldwide acknowledge their responsibility to manage patients' home health needs by getting to know them as individuals and learning about their lives in the context of an ongoing relationship. They coordinate patient care in the community, respond to patient/family-identified needs, and help patients identify and prioritize goals. ${ }^{37}$ Furthermore, primary home health care nurses acknowledge the dignity, culture, values, beliefs, and rights of individuals ${ }^{38}$; thereby, nurses are an integral part of forthcoming changes in primary health care delivery. Community nurses can be considered providers, enabling patients/families to report higher levels of satisfaction than their urban counterparts for overall case, pain, and symptom management. ${ }^{39}$

\section{Limitations}

Findings should be interpreted in lieu of these limitations. Data were collected using a convenience sample; probability sampling methods were not incorporated. Selection bias is another concern. Most nurses practiced in urban settings; those working in more remote areas were not surveyed. Some questions (specific countries) had missing data due to translation issues, resulting in nonrandom missing information. Other data points were misinterpreted; for example, a question asked about number of weekly visits. Some respondents reported $>100$ visits; this question was excluded from those respondents. WHO low-income countries and level 1 and 2 PCD countries were not well represented. To protect anonymity, researchers collapsed PCD levels 1 and 2, making interpretations more challenging. These limitations pose challenges in that findings may not be generalizable to other countries in income and PC levels or to other home health care providers within the countries sampled.

\section{Summary}

Community home health care nurses are on the frontline and provide comprehensive patient/family-centered care, contributing to patient comfort, fewer hospitalizations, and higher home death rates, which are often desired by patients and serve as a clinical outcome in the community. ${ }^{40}$ The majority of patients who need home-based PC live in lowincome and middle-income settings. These services should be a major health priority in those countries. Home health care nurses should be well resourced and equipped to deliver 
PC that is so desperately needed; educational opportunities can mobilize the nursing workforce to optimize home health care for PC provision and improve patient and country outcomes.

\section{Author Disclosure Statement}

No competing financial interests exist.

\section{References}

1. Silbermann M, Baider L, Saleem A, et al:: The overwhelming contribution of women to the development and establishment of palliative care as a recognized medical specialty. Br J Cancer Res 2018;1:162-166.

2. Senel G, Silbermann M: Cultural challenges in implementing programs in emerging countries. Palliat Med Hosp Care 2017. DOI: 10.17140/PMH.COJ-SE-1-101.

3. Tang L, Silbermann M: Palliative care gains roots in China. J Palliat Care Med 2017;7:1-3.

4. Silbermann ME: Palliative Care: Perspectives, Practices and Impact on Quality of Life. A Global view. New York: Nova Science Publishers, 2017.

5. Hacikamiloglu E, Utku ES, Cukurova Z, et al.: Community palliative care in Turkey: A collaborative promoter to a new concept in the Middle East. J Public Health Manag Pract 2016;22:81-88.

6. Sabar R, Katz GJ, Silbermann MJ: Family carers and the home hospice patient in Israel: A pilot study of the need for a multi-cultural perspective. J Fam Med 2016;3:1082.

7. Bar-Sela G, Schultz M, Elshamy K, et al.: Training for awareness of one's own spirituality: A key factor in overcoming barriers to the provision of spiritual care to advanced cancer patients by doctors and nurses. Palliat Support Care 2019;17:345-352.

8. World Health Organization: Strengthening of palliative care as a component of comprehensive care throughout the life course (67th World Health Assembly). Geneva, Switzerland: WHO; 2014. http://apps.who.int/medicinedocs/documents/ s21454en/s21454en.pdf (Last accessed May 25, 2018).

9. World Health Organization: Assessing national capacity for the prevention and control of noncommunicable diseases: report of the 2015 global survey Geneva, Switzerland: WHO; 2016. http://apps.who.int/iris/bitstream/handle/10665/ 246223/9789241565363-eng.pdf;jsessionid=D1D3B3189E5 32CC1568841C71ADB818B?sequence=1\&TSPD_101_R0= 13566a6a80ca155434ed42b63bf07773j1b000000000000000 $271617 \mathrm{a} 61 \mathrm{ffff} 00000000000000000000000000005 \mathrm{~b} 7 \mathrm{de} 7$ fc0064dd669a (Last accessed May 20, 2018).

10. World Health Organization: Palliative care fast fastsheet. Geneva, Switzerland: WHO. 2018. www.who.int/mediacentre/ factsheets/fs402/en (Last accessed June 1, 2018).

11. Barrett A, Terry DR, Le Q, Hoang H: Factors influencing community nursing roles and health service provision in rural areas: A review of literature. Contemp Nurse 2016;52: 119-135.

12. Cramm JM, Nieboer AP: Self-management abilities and quality of life among frail community-dwelling individuals: The role of community nurses in the Netherlands. Health Soc Care Community 2017;25:394-401.

13. Ball J, Philippou J, Pike G, Sethi GK: Survey of District and Community Nurses in 2013: Report to the Royal College of Nursing. London: Royal College of Nursing, 2014.
14. Roden J, Jarvis L, Campbell-Crofts S, Whitehead D: Australian rural, remote and urban community nurses' health promotion role and function. Health Promot Int 2016;31: 704-714.

15. Schaffer MA, Keller LO, Reckinger D: Public health nursing activities: Visible or invisible? Public Health Nurs 2015;32:711-720.

16. Department of Health and Human Services Tasmania: BAPC Community nursing palliative care snapshot survey Tasmania: Department of Health and Human Services. 2016. https://www.dhhs.tas.gov.au/palliativecare (Last accessed May 18, 2018).

17. Devlin M, McIlfatrick S: Providing palliative and end-oflife care in the community: The role of the home-care worker. Int J Palliat Nurs 2010;16:195-203.

18. Walshe C, Luker KA: District nurses' role in palliative care provision: A realist review. Int J Nurs Stud 2010;47: 1167-1183.

19. De Lima L, Pastrana T: Opportunities for palliative care in public health. Annu Rev Public Health 2016;37:357-374.

20. Lynch T, Connor S, Clark D: Mapping levels of palliative care development: A global update. J Pain Symptom Manage 2013;45:1094-1106.

21. World Health Organization: World Bank Income Groups Geneva, Switzerland: WHO. 2018. www.who.int/healthinfo/ global_burden_disease/definition_regions/en (Last accessed July 10,2018$)$.

22. Gantz NR, Sherman R, Jasper M, et al.: Global nurse leader perspectives on health systems and workforce challenges. J Nurs Manag 2012;20:433-443.

23. Ingleton $\mathrm{C}$, Gardiner $\mathrm{C}$, Seymour JE, et al.: Exploring education and training needs among the palliative care workforce. BMJ Support Palliat Care 2013;3:207-212.

24. Pesut B, Potter G, Stajduhar K, et al.: Palliative approach education for rural nurses and health-care workers: A mixed-method study. Int J Palliat Nurs 2015;21:142-151.

25. Shaffer FA, Davis CR, To Dutka J, Richardson DR: The future of nursing: Domestic agenda, global implications. J Transcult Nurs 2014;25:388-394.

26. Walshe C, Todd C, Caress A, Chew-Graham C: Patterns of access to community palliative care services: A literature review. J Pain Symptom Manage 2009;37:884-912.

27. Greiner L, Buhr B, Phelps D, et al.: A palliative care needs assessment of health care institutions in Wisconsin. J Palliat Med 2003;6:543-556.

28. IBM SPSS Statistics 22.0. Chicago, IL: SPSS, Inc., 2014.

29. SAS 9.4. Cary, NC: SAS Institute, Inc., 2014.

30. Kaasa S, Loge JH, Aapro M, et al.: Integration of oncology and palliative care: A Lancet Oncology Commission. Lancet Oncol 2018;19:e588-e653.

31. Ferrell BR, Twaddle ML, Melnick A, Meier DE: National Consensus Project Clinical Practice Guidelines for Quality Palliative Care Guidelines, 4th Edition. J Palliat Med 2018. [Epub ahead of print]; DOI: 10.1089/jpm.2018.0431.

32. Coursera: Palliative Care: It's Not Just Hospice Anymore Specialization Denver, CO: University of Colorado. 2019. https://www.coursera.org/specializations/palliative-care (Last accessed January 16, 2019).

33. Elliott L, Kennedy C, Raeside R: Professional role identity in shaping community nurses' reactions to nursing policy. J Nurs Manag 2015;23:459-467.

34. Koy V: Policy recommendations to enhance nursing education and services among Asian member countries. Int $\mathbf{J}$ Adv Med 2015;2:324-329. 
35. Fitch MI, Fliedner MC, O'Connor M: Nursing perspectives on palliative care 2015. Ann Palliat Med 2015;4:150-155.

36. Nkowane AM, Khayesi J, Suchaxaya P, et al.: Enhancing the role of community health nursing for Universal Health Coverage: A survey of the practice of community health nursing in 13 countries. Ann Nurs Pract 2016;3:1042.

37. Nowels D, Jones J, Nowels CT, Matlock D: Perspectives of primary care providers toward palliative care for their patients. J Am Board Fam Med 2016;29:748-758.

38. Australian Primary Health Care Nurses Association (HPNA): Blog for Nurses Working in Primary Health Care Melbourne, Australia: HPNA. 2016. www.apnanurses.asn.au (Last accessed October 13, 2018).

39. Medicare Payment Advisory Commission: Report to the Congress: Medicare Payment Policy. Washington, DC: Medicare, 2017.
40. Murakami N, Tanabe K, Morita T, et al.: Impact of a sixyear project to enhance the awareness of community-based palliative care on the place of death. J Palliat Med 2018;21: 1494-1498.

Address correspondence to: Jeannine M. Brant, PhD, APRN, AOCN, FAAN Collaborative Science and Innovation Billings Clinic Montana State University College of Nursing 2651 North Bridger Billings, MT 59102

E-mail: jbrant@billingsclinic.org

APPENDIX

\section{A Global Home Health Nursing Care Assessment}

Please read each of the following items and then indicate your response by marking the appropriate selection unless otherwise specified.

\section{Demographics}

1. What is your age?

2. Select your sex:

_ Male

Female

3. Are you currently employed as a home health nurse, community health nurse, field nurse, or administrator of such a program?

- Yes

- No

4. If you are employed as a home health nurse, community health nurse, field nurse, or administrator describe your current employment:

Full time

Part time

Per diem

On call

Contract

Other

5. What country are you currently working in?

\begin{tabular}{llll} 
U.S. & \multicolumn{1}{c}{ Oman } & Yemen & Tanzania \\
New Zealand & Pakistan & Myanmar & - Kenya \\
Egypt & Afghanistan & Uurma & - Uganda \\
Saudi Arabia & Jordan & - Iraq & - Tran \\
Cyprus & Israel & - Palestine & - Uurkey \\
Morocco & Sudan & - Lebanon & - \\
Europe, please specify: &
\end{tabular}

6. Which of the following best describes the area you provide care in?

Rural (places, territories that have $<50,000$ people)

Urban (cities having $\geq 50,000$ or more people) 


\section{Education}

7.1 Select from the following diplomas or degrees that you have received:

Associate Degree in Nursing

Bachelor Degree in Nursing

Bachelor Degree in Community Nursing

Bachelor Degree in a related field

Diploma in Nursing

_ Doctor of Nursing Practice

Doctor of Nursing Science or Nursing Doctorate

Home Health Aide Certification

Master's Degree in Nursing or related health field

Master's Degree in a related health field

$\mathrm{PhD}$ in Nursing

$\mathrm{PhD}$ in a related field

Practical Nursing or Vocational Nursing Diploma

None

Other, please specify:

7.2 In what country did you obtain the above education?

\begin{tabular}{llll} 
U.S. & \multicolumn{1}{c}{ Oman } & Yemen & Tanzania \\
New Zealand & - Pakistan & Myanmar & - Kenya \\
Egypt & Afghanistan & Burma & - Uganda \\
Saudi Arabia & Jordan & Iraq & - Iran \\
Cyprus & Israel & - Palestine & - Turkey \\
Morocco & Sudan & - Lebanon & - \\
Europe, please specify: & \\
\hline Other, please specify:
\end{tabular}

\section{Nursing Career Information}

8. How many years of nursing experience do you have?

9. Please indicate any of the clinical areas listed below in which you have received continuing education: (Check all that apply)

None

Adult Health

Community Health

Family Health

Geriatrics/Gerontology

Home Health

Hospice Care

_ Oncology

_ Palliative Care

Pediatrics

Parish/Faith Community

Primary Health Care

_ Public Health

_ Psychiatric/Mental Health

Rehabilitation

Other, please specify:

\section{Nursing Care Provided}

10. Are you currently providing care mostly in your primary language?

_ Yes, please specify your language

No 
What age categories do you care for in the community?

Yes No

Prenatal, perinatal, newborn

Pediatrics

Adolescents

Young adults

Middle age

Elderly

Male

Female

11. What is the most prevalent socioeconomic class that you provide care for?

Poor (No Income)

Low Income

Middle Income

High Income

All of the Above

12. In your opinion, how accepting is your community to the care you offer? (circle one)

Not at all Somewhat Usually Very

$\begin{array}{llll}0 & 1 & 2 & 3\end{array}$

13. How often do you perform the following duties within your role? (Circle)

\begin{tabular}{|c|c|c|c|c|c|}
\hline & & Never & Sometimes & Frequently & Always \\
\hline 13.1 & $\begin{array}{l}\text { Activities of Daily Living (e.g., meal preparation, basic } \\
\text { hygiene, transportation) }\end{array}$ & 0 & 1 & 2 & 3 \\
\hline 13.2 & Antibiotics/IV drug management & 0 & 1 & 2 & 3 \\
\hline 13.3 & Advance Care Planning & 0 & 1 & 2 & 3 \\
\hline 13.4 & Bereavement/Grief support & 0 & 1 & 2 & 3 \\
\hline 13.5 & Cancer Treatment & 0 & 1 & 2 & 3 \\
\hline 13.6 & Discuss goals of care with family & 0 & 1 & 2 & 3 \\
\hline 13.7 & Discuss goals of care with patient & 0 & 1 & 2 & 3 \\
\hline 13.8 & Educating Family & 0 & 1 & 2 & 3 \\
\hline 13.9 & Educating Patient & 0 & 1 & 2 & 3 \\
\hline 13.10 & Emotional Support & 0 & 1 & 2 & 3 \\
\hline 13.11 & End-of-Life Care & 0 & 1 & 2 & 3 \\
\hline 13.12 & $\begin{array}{l}\text { Health Maintenance (e.g., blood pressure monitoring, blood } \\
\text { glucose checks, laboratory draws) }\end{array}$ & 0 & 1 & 2 & 3 \\
\hline 13.13 & Medication Administration (e.g., oral, insulin) & 0 & 1 & 2 & 3 \\
\hline 13.14 & Occupational Therapy & 0 & 1 & 2 & 3 \\
\hline 13.15 & Pain Assessment and Management & 0 & 1 & 2 & 3 \\
\hline 13.16 & Palliative Care & 0 & 1 & 2 & 3 \\
\hline 13.17 & Physical Therapy or Physiotherapy & 0 & 1 & 2 & 3 \\
\hline 13.18 & Preventative Health Education & 0 & 1 & 2 & 3 \\
\hline 13.19 & Patient Safety and Quality Improvement & 0 & 1 & 2 & 3 \\
\hline 13.20 & Speech Therapy & 0 & 1 & 2 & 3 \\
\hline 13.21 & Symptom Assessment and Management & 0 & 1 & 2 & 3 \\
\hline 13.22 & Wound Care & 0 & 1 & 2 & 3 \\
\hline
\end{tabular}

14. Please specify any other service(s) not listed above that you perform regularly:

15. On a weekly basis, approximately how many home visits do you make?

16. Do you have support staff available (e.g., home health aides, CNAs, uncertified support staff)?

No (skip to question 17)

Yes (if yes, please answer subset questions below) 
16.1 What level of education and/or certification is required for your support staff?

Certified Nursing Assistant

Home health aide

None

O Other, please specify:

16.2 Do you believe you have enough support staff team members to provide quality care?
Not at all
0
Somewhat
Mostly
2
Absolutely
3

17. What other disciplines do you collaborate with? (Select all that apply)
Homeopathic / Naturopathic
Nutritionist / Dietician
_ Occupational Therapy
Physical Therapy
_ Primary Health Care Provider
__ Psychologist / Psychiatrist
_ Religious Support
_ Respiratory Therapy
_ Social Work
__ Specialty Physician, please specify:
_ Specialty Nurse, please specify:
__ Other, please specify:

_ None

\section{Satisfaction}

18. In your setting, how satisfied are you with each of the following (Circle)

\begin{tabular}{|c|c|c|c|c|c|}
\hline & & $\begin{array}{c}\text { Very } \\
\text { dissatisfied }\end{array}$ & Dissatisfied & Satisfied & $\begin{array}{c}\text { Very } \\
\text { satisfied }\end{array}$ \\
\hline 18.1 & Access to necessary medications & 0 & 1 & 2 & 3 \\
\hline 18.2 & Access to needed medical supplies & 0 & 1 & 2 & 3 \\
\hline 18.3 & Communication between patient and provider & 0 & 1 & 2 & 3 \\
\hline 18.4 & Communication between nurse and provider & 0 & 1 & 2 & 3 \\
\hline 18.5 & Communication with patient on treatment decisions & 0 & 1 & 2 & 3 \\
\hline 18.6 & Pain Management provided & 0 & 1 & 2 & 3 \\
\hline 18.7 & Family Support provided & 0 & 1 & 2 & 3 \\
\hline 18.8 & Patient goals are continually discussed and evaluated & 0 & 1 & 2 & 3 \\
\hline 18.9 & Patients have adequate information about care alternatives & 0 & 1 & 2 & 3 \\
\hline 18.10 & Religious or Spiritual support provided & 0 & 1 & 2 & 3 \\
\hline 18.11 & Symptom Management provided & 0 & 1 & 2 & 3 \\
\hline
\end{tabular}

19. Are there other areas of care that you are specifically satisfied or dissatisfied with?

No
Yes, please specify:

\section{Barriers}

20. The following items are possible barriers to providing optimal care to patients. To what extent is each a barrier in your setting? (Circle)

\begin{tabular}{|c|c|c|c|c|c|}
\hline & & Not at all & Somewhat & Moderate & Severe \\
\hline 20.1 & Communication difficulties with patients & 0 & 1 & 2 & 3 \\
\hline 20.2 & Communication difficulties with families & 0 & 1 & 2 & 3 \\
\hline 20.3 & Communication difficulties among the interdisciplinary team & 0 & 1 & 2 & 3 \\
\hline 20.4 & Cultural beliefs influencing care & 0 & 1 & 2 & 3 \\
\hline 20.5 & Lack of access to end-of-life or hospice services & 0 & 1 & 2 & 3 \\
\hline 20.6 & Lack of access to opioid medications for pain management & 0 & 1 & 2 & 3 \\
\hline 20.7 & Lack of community awareness of services provided & 0 & 1 & 2 & 3 \\
\hline 20.8 & Lack of Funding & 0 & 1 & 2 & 3 \\
\hline
\end{tabular}


20.13 Religious or Spiritual beliefs influencing care

21. Please specify any other significant barriers you encounter that are not listed above:

\section{Strengths, Suggestions, and Training}

22. Please identify one thing that your facility is doing well to provide in-home care:

23. What suggestions do you have to improve quality of care for your patients?

24. What training topics do you feel would be most beneficial for home health courses?

25. Do you have any access to the following resources?

\begin{tabular}{llll}
\hline & Yes & No \\
\hline
\end{tabular}

Continuing professional education/courses/conferences

Professional journals

Support from other nurses

Support from other health professionals

Support from volunteers

Access to a mentor

Professional nursing organization membership

Access to a library, librarian, or electronic library

Internet

E-mail

26. Which of the following do you identify as barriers to accessing educational opportunities?

\begin{tabular}{lll}
\hline & Yes
\end{tabular}

Appropriate education not readily available

Geographic

Financial

Time

No relief staff to cover workload while at a conference

Employer resistance

Personal

Other, please specify

27. How would you like to receive continuing education?

Internet meeting

In person meeting

Self-learning educational module/offering

Other, please specify: 
Appendix A1. Item Mean and Standard Deviation

Duties

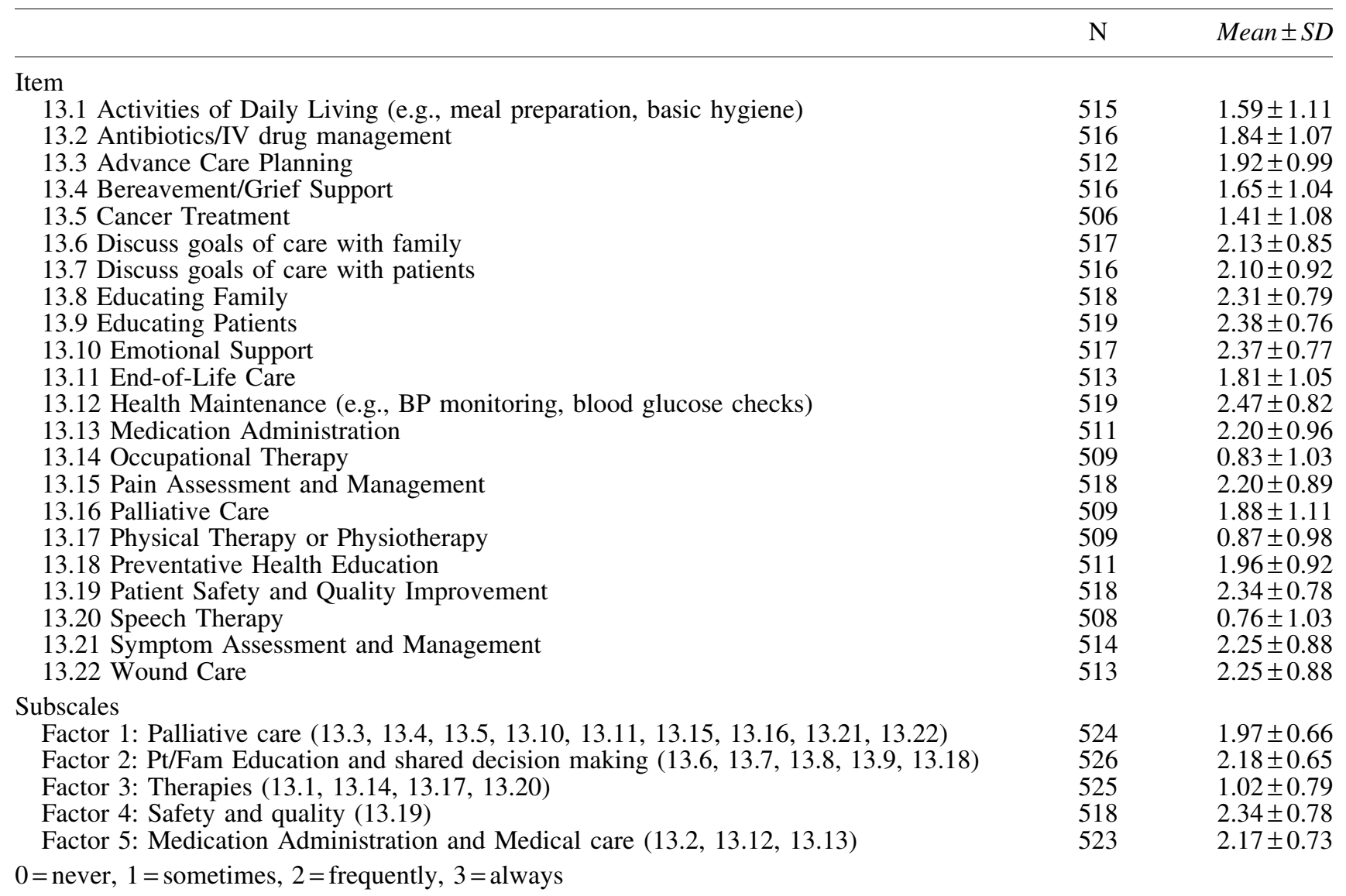

Satisfiers

$\mathrm{N}$

Mean $\pm S D$

Item

18.1 Access to Necessary medications

18.2 Access to Needed medical supplies

18.3 Communication between patient and provider

495

$1.87 \pm 0.78$

18.4 Communication between nurse and provider

18.5 Communication with patient on treatment decisions

18.6 Pain management provided

18.7 Family support provided

18.8 Patient goals are continually discussed and evaluated

18.10 Religious or Spiritual support provided

18.11 Symptom management provided

Subscales

Patient and Family Care (18.5, 18.6, 18.7, 18.8, 18.9, 18.11)

$500 \quad 1.89 \pm 0.67$

$495 \quad 1.89 \pm 0.75$

Access to Medications and Supplies $(18.1,18.2)$

$496 \quad 2.11 \pm .69$

Provider Communication (18.3, 18.4)

479

$1.88 \pm 0.93$

$0=$ very dissatisfied, $1=$ dissatisfied, $2=$ satisfied, $3=$ very satisfied

\section{Barriers}

Item

21.1 Communication difficulties with patients

21.2 Communication difficulties with families
$\mathrm{N}$

Mean $\pm S D$ 
ApPendix A1. (Continued)

\begin{tabular}{lcc}
\hline Barriers & & \\
& $\mathrm{N}$ & Mean $\pm S D$ \\
\hline 21.3 Communication difficulties among the interdisciplinary team & 512 & $1.11 \pm 0.81$ \\
21.4 Cultural beliefs influencing care & 508 & $1.13 \pm 0.88$ \\
21.5 Lack of access to end-of-life or hospice services & 511 & $1.33 \pm 1.01$ \\
21.6 Lack of access to opioid medications for pain management & 507 & $1.11 \pm 0.99$ \\
21.7 Lack of community awareness of services provided & 503 & $1.32 \pm 0.84$ \\
21.8 Lack of Funding & 501 & $1.49 \pm 1.03$ \\
21.9 Lack of Policy and Guidance & 505 & $1.35 \pm 0.98$ \\
21.10 Lack of Training for Staff & 507 & $1.17 \pm 0.93$ \\
21.11 Language Barrier & 507 & $0.74 \pm 0.80$ \\
21.12 Personnel Shortages & 511 & $1.55 \pm 1.03$ \\
21.13 Religious or Spiritual beliefs influencing care & 513 & $0.92 \pm 0.84$ \\
21.14 Time Constraints & 510 & $1.28 \pm 0.88$ \\
Subscales & & \\
Factor 1: Lack of PC services (21.5, 21.6) & 513 & $1.22 \pm 0.89$ \\
Factor 2: Lack of infrastructure $(21.7,21.8,21.9,21.10)$ & 512 & $1.33 \pm 0.75$ \\
Factor 3: Pt/Fam Communication (21.1, 21.2) & 522 & $1.13 \pm 0.69$ \\
Factor 4: Culture/Religion (21.4, 21.13) & 518 & $1.02 \pm 0.76$ \\
Factor 5: Personnel and time resources $(21.12,21.14)$ & 517 & $1.41 \pm 0.78$ \\
Factor 6: Language (21.11) & 519 & $1.09 \pm 0.73$ \\
Factor 7: IDT communication (21.3) & 512 & $1.11 \pm 0.81$ \\
$0=$ not at all, 1 = somewhat, 2=moderate, 3= severe & & \\
\hline
\end{tabular}

BP; blood pressure; IDT, interdisciplinary team; PC, palliative care; SD, standard deviation. 